\title{
7
}

\section{Agency Laundering and Information Technologies}

There have been numerous examples of automated decision systems going wrong in consequential ways. In 2018, an Uber-automated driving system failed to recognize a bicyclist, whom it struck and killed. ${ }^{1}$ In 2012, the Target Corporation received international attention when, based on predictive analytics and an automated advertising system, it sent fliers targeting women seeking prenatal products to a minor before she had revealed her pregnancy to one of her parents. ${ }^{2}$ In 2017 , the news organization ProPublica was able to use Facebook's automated system to make an ad buy targeting users with anti-Semitic affiliations. ${ }^{3}$ The system even suggested additional racist categories to make the ad purchase more effective. As we have discussed, COMPAS yields different results depending on the race and ethnicity of defendants. ${ }^{4} \mathrm{~A}$ common element in these stories is that the technology itself plays an important role. The existence and use of technological systems are a key part of the explanation of the events. Whether (and how) the technologies are relevant in assessing moral responsibility is considerably more complex.

Our discussion so far has focused on how persons deserve to be treated in light of their autonomy and conditions necessary for people to act autonomously. This chapter instead considers the moral agency of those who deploy information technologies (as collectors of big data, users of algorithmic decision systems, developers of social media sites, and so on).

We will argue that a type of moral wrong that can arise in using automated decision tools is "agency laundering." At root, agency laundering involves obfuscating one's moral responsibility by enlisting a technology or process to take some action and letting it forestall others from demanding an account for bad outcomes that result. Laundering is not unique to information technologies. However, we

1 Levin and Wong, "Self-Driving Uber Kills Arizona Woman in First Fatal Crash Involving Pedestrian."

2 Duhigg, "How Companies Learn Your Secrets." Note that a number of commentators believe the story makes too close a connection between predictive analytics and pregnancy-related advertising. There are reasons to send such advertising to people who are not pregnant, the advertising may have been based on criteria unrelated to pregnancy, and others. Harford, "Big Data."

3 Angwin, Varner, and Tobin, "Facebook Enabled Advertisers to Reach 'Jew Haters."

4 Angwin et al., "Machine Bias," May 23, 2016. 
argue that the concept of agency laundering helps understand important moral problems in several recent cases involving algorithmic systems. The moral concerns are not merely that values are instantiated within such systems, but that intermingling moral wrongs with morally permissible processes undermines a fundamental facet of responsibility itself.

We begin, in Section 7.1, with an account of responsibility to ground our arguments. In Section 7.2, we develop our account of agency laundering and explain its moral salience. In Sections 7.3 through 7.6, we offer several case studies that allow us to apply and further explain our conception. One is Facebook's targeted advertising system and its response to complaints that it allows users to make racist ad purchases. This is a clear case of agency laundering. Next, we consider Uber's use of algorithmic systems in its driver-management apps and show how we can distinguish cases of agency laundering from non-agency laundering in structurally similar cases. We then turn to public-sector uses, showing how school districts can launder agency in teacher-evaluation cases and how courts can avoid agency laundering by clarifying responsibility for decision systems. In Section 7.7, we explain how agency laundering is distinct from other concepts, especially the "responsibility gap." 5

\subsection{AGENCY AND RESPONSIBILITY}

Our argument turns on the concept of responsibility. For a person to launder his or her agency requires that he or she be a moral agent in the first place, and being a moral agent requires that one be in some sense morally responsible. In this section, we first distinguish several facets of responsibility and how they relate to one another, which helps structure our understanding of agency laundering in the following section. Then, we offer a substantive account of responsibility, which will ground our understanding of the moral wrongs associated with agency laundering.

\subsubsection{The Structure of Responsibility}

In Punishment and Responsibility, H. L. A. Hart describes a ship captain who gets drunk, wrecks their ship, is convicted of criminal negligence, and whose employer is held financially liable for the loss of life and property. ${ }^{6}$ Hart's allegory and the distinctions he offers are useful in grounding our account. ${ }^{7}$

To begin, a person might be responsible in virtue of a role. In Hart's example, a person is responsible for a ship's safety in virtue of the fact that they are the captain.

5 Matthias, "The Responsibility Gap: Ascribing Responsibility for the Actions of Learning Automata."

6 Hart, Punishment and Responsibility; Essays in the Philosophy of Law, 211.

7 Our account of the structure of responsibility follows closely those articulated by Nicole Vincent and Chris Kutz. Both Vincent and Kutz recast Hart's ship captain case to distinguish various facets of responsibility. See Vincent, "A Structured Taxonomy of Responsibility Concepts"; Kutz, "Responsibility." 
A person's role requires them to anticipate events in some domain and to take actions to avoid bad outcomes in that domain. ${ }^{8}$ A ship captain should anticipate bad weather and obstacles and plot course accordingly. Parents should anticipate their children's needs and plan ways to address them. Financial advisors should anticipate client needs and economic forecasts and guide clients' actions suitably. Although one's well-defined social roles (ship captain, parent, financial trustor) may give rise to specific responsibilities, the idea of role responsibility is broad enough to encompass general obligations one has as a moral agent. So, for example, adults have a responsibility to operate heavy machinery carefully, regardless of their specialized social roles; community members have a responsibility to pay applicable taxes; and people engaged in commerce have a responsibility to bargain in good faith. ${ }^{9}$

Second is causal responsibility or the link between an agent's action (or omission or disposition ${ }^{10}$ ) and an event that results from it. Chris Kutz calls this explanatory responsibility, as causation generally explains an event. ${ }^{11}$ Any explanation of the shipwreck that ignores the captain and the captain's drinking would be inadequate.

Causal responsibility in this sense does not entail moral responsibility. That is because of the third facet, capacity responsibility, which relates to whether an agent has the requisite capacities to be responsible for an outcome. One may lack capacity responsibility due to pathology or pre-reflective, non-deliberative action. In Hart's example, it is possible that a ship captain's drinking was due to extreme, clinical anxiety, in which case their intoxication is something they caused, but for which they lacked the required capacity to be responsible. ${ }^{12}$ Alternatively, one may lack capacity due to lack of access to relevant information. That is, an agent must be in a position to access certain facts about their actions and their significance in order to be retrospectively morally responsible for them.

We can sum up the structure so far as follows. For a person to be (retrospectively) morally responsible - which is to say morally liable - for some event or outcome, they must have some role responsibility (either a specific duty that attaches to a social role or a general duty as a moral agent) and they must be causally responsible for the outcome (which is to say an action of theirs is a key part of the explanation of

8 Antony Duff calls this "prospective" responsibility. See Duff, "Responsibility." Here we should note that we are only discussing morally justifiable roles, where the holders of role responsibility are themselves moral agents. Hence, being assigned a role within a criminal organization, or being assigned a role when one lacks the capacity to act morally, cannot confer role responsibility in the required sense.

9 Goodin, "Responsibilities"; Goodin, "Apportioning Responsibilities"; Williams, "Responsibility as a Virtue"; Vincent, "A Structured Taxonomy of Responsibility Concepts."

10 For the sake of simplicity, we will refer to "actions" in discussing responsibility. However, our account extends to omissions and dispositions. Note, too, that causal responsibility is complicated in overdetermination cases. But those cases do not affect our analysis here.

${ }^{11}$ Kutz, "Responsibility," 549.

12 This, of course, may not absolve the captain completely. Fischer and Ravizza, Responsibility and Control: A Theory of Moral Responsibility, 49-51, for an explanation of "tracing" responsibility to prior actions. 
the outcome). Moreover, they must have capacity responsibility. That is, their action must not be the result of some pathology or pre-reflective action, and they must in some sense have access to relevant information. ${ }^{13}$ For the remainder of the chapter we use "moral responsibility" and "moral liability" interchangeably, and they will refer to this conjunction of role responsibility, causal responsibility, and capacity responsibility.

\subsubsection{The Content of Responsibility}

With these distinctions in mind, we can turn to the content of moral responsibility. In other words, once we have determined that an actor has some kind of role responsibility, is causally responsible for an outcome, and has the requisite capacity to be responsible, there is a further question about what this responsibility means. There are two key features of the view we endorse here. First, moral responsibility is fundamentally relational and grounded in social roles. Second, being morally responsible for some action means that one is accountable for (and should be able to provide an account of) their reasons for that action.

The view that moral responsibility is fundamentally relational owes a great deal to Peter Strawson's seminal article, "Freedom and Resentment."14 Holding a person responsible by forming reactive attitudes about him or her (e.g., appreciation, admiration, disdain) is a feature of interpersonal relationships in which one regards the other as a participant. We might resent the captain for getting drunk and steering their ship onto the rocks, or we might admire them for their skill in guiding the ship to safety during a storm. However, we do not form such reactive attitudes toward entities that are not participants in relationships; resentment and admiration are not reasonable reactions to the actions of infants or machines. If an autopilot algorithm successfully steers the ship to safety, it would be appropriate to be impressed, baffled, or happy, but not to feel respect and admiration for the algorithm itself.

Despite these important insights, precisely what (if anything) justifies reactive attitudes is a further question. As Marina Oshana points out, the mere fact (if it is) that people are committed to the appropriateness of their reactive attitudes toward (some) people for (some of) their actions cannot suffice to explain why those reactions are appropriate. We do not call a person morally responsible just because others regard them as responsible. Rather, "we call a person an appropriate subject of reactive attitudes because the person is [morally] responsible." 15

13 There remain some controversial issues, including for example Frankfurt-style cases in which one may be responsible or not regardless of whether they do or do not know how their actions will be causally effective. But the issues in those cases turn on the link between causal responsibility and the ability to do otherwise. That does not affect our arguments.

14 Strawson, "Freedom and Resentment."

15 Oshana, "Ascriptions of Responsibility," 1997, 75 (emphasis added). 
While keeping in mind the important social function of responsibility attributions, our view aligns with the constellation of views for which an agent's moral responsibility turns on whether they are answerable or accountable for their actions. Angela Smith, for example, argues that for an agent to be morally responsible for something is for the agent to be "open, in principle, to demands for justification regarding that thing." And blame is in effect a demand that the agent "justify herself." Oshana's view is related. She articulates an accountability view according to which a person is responsible if, and only if, "it ought to be the case that the person account for her behavior." Giving such an account requires a person to provide a statement of their "beliefs or intentions" for their actions. "Thus," Oshana explains, " $\mathrm{X}$ is accountable for $\mathrm{Y}$ ' can be unpacked as 'It is appropriate that $\mathrm{X}$ explain her intentions in doing (or being) Y'." ${ }^{\prime 17}$

The key insight of the accountability views is that they identify not only who is morally responsible but what that responsibility involves. Specifically, it is justifiable to ask the responsible agent to account for their actions, omissions, or dispositions. They should be able to explain their intentions, reasons, and actions in terms that other relationship participants can understand.

\subsection{AGENCY LAUNDERING}

With our discussion of responsibility in mind, we can return to the chapter's central argument. Using an automated process to make decisions can allow a person to distance themself from morally suspect actions by attributing the decision to the system, thereby laundering their agency. Put slightly differently, invoking the complexity or automated nature of a decision system to explain an outcome allows

16 Smith, "Attributability, Answerability, and Accountability," 577-578. Within this group of views, there is substantial debate about whether person $\mathrm{X}$ is responsible for $\mathrm{Y}$ in virtue of $\mathrm{Y}$ being attributable to $\mathrm{X}$, of X being answerable for $\mathrm{Y}$, or of $\mathrm{X}$ being accountable for $\mathrm{Y}$. Scanlon's view focuses on attributability (Scanlon 2008). Shoemaker distinguishes between attributability, answerability, and accountability (Shoemaker 2011). Smith (like Shoemaker) distinguishes a thing being attributable to a person and that person being responsible for it; however, she views accountability as a species of answerability. What is important for our purposes is that each of the views in this constellation recognizes that the content of responsibility claims is that responsible agents are those for whom it is appropriate, or for whom it ought to be the case, that they provide an account of their intentions, interests, and reasons for an action.

17 Oshana, "Ascriptions of Responsibility," 1997, 77. Fischer and Ravizza provide an accountability view that bridges (a) Strawson's attention to the social function of holding others responsible by way of reactive attitudes and (b) accountability views' attention to reasons. Specifically, they maintain that an agent is responsible if they are an apt target of reactive attitudes. More important here, though, is that being morally responsible for actions requires that agents exercise "guidance control." That requires that agents be at least weakly reasons-responsive, which is to say that where the agent has access to strong reasons in favor or against an action, they will act in accordance with those reasons. It also requires that the source of actions be the agent, which is to say that the reason-responsiveness is internal to the agent. Fischer and Ravizza, Responsibility and Control: A Theory of Moral Responsibility, 31-41. 
a party to imply that the action is something for which they are not morally responsible.

Compare money laundering. ${ }^{18}$ Where one has such large amounts of illicit cash that spending it or placing it into legitimate financial instruments would be suspicious, one can launder it by mingling it with other, legitimate streams of income so that the illicit cash appears legal. For example, one might add the illegal cash to money received in a legal, cash-dependent business. ${ }^{19}$ The bad thing (income from an illicit source) is hidden by the existence of some other, similar phenomenon. To be clear, we are not making an argument by analogy; decisions are not like cash. Rather, the point is that it is possible to obscure the source of responsibility for actions and make them appear unsuspicious by mingling them with other actions.

Consider a minor example ("Chair"). Suppose that Cheese State University vests department chairs with control over curriculum. A chair and several members of their department would like to get rid of phlogiston studies ("P-studies") because they think it is unimportant. The chair could do this unilaterally by removing courses, reassigning instructors, and altering degree requirements but wants to avoid the wrath of the department phlogistologists. The chair therefore delegates curriculum decisions to a committee of people who they know want to eliminate P-studies. When P-partisans complain, the chair responds that it was the committee's decision, though the chair knew from the beginning what that decision would be. By impaneling a committee to ensure the results the chair wanted, the chair obscures their own role in the decision. The committee appears to be the relevant power, though it remained the chair.

There are several features of Chair to address initially. First is that the chair had legitimate institutional authority to make the decision, and if they had moved to eliminate P-studies unilaterally it would have happened. The chair's institutional authority is a form of role responsibility for their department's curriculum. The chair has the responsibility to anticipate educational needs, department resources, student demand, scholarly trends, and so forth, and to ensure that the department's offerings adequately address them. And the chair's de facto power to alter the curriculum is a form of causal responsibility; when the curriculum changes, the chair's actions are an essential part of the explanation why.

Second, although the chair has power to make the decision, they draw in a separate body by giving the committee some degree of causal responsibility. Because the curriculum change would not occur without the committee's work, the committee is an essential part of the explanation for the curriculum change. It is not the only cause, as it is mixed with the chair's actions. Third, when the chair forms the committee, they imply it is neutral, would weigh evidence fairly, and might act

1818 U.S. Code $\$ 1956$ - Laundering of monetary instruments.

19 Other aspects of money laundering are about concealing identities of agents, for example by routing illicit money through shell corporations and bank accounts in permissive jurisdictions. 
in a way that the chair doesn't anticipate. But that's a ruse - ex hypothesi, the chair knows that the committee will act just as the chair wishes.

Fourth, the chair's actions obscure their causal responsibility with respect to the curriculum. The chair is able to obscure the fact that they orchestrated the result by making the committee partially causally responsible (i.e., a key part of the explanation) for the result. Fifth, although the chair appears to fulfill their responsibility in shepherding the curriculum, appointing the committee obscures the chair's designs to eliminate P-studies.

The following is a definition of agency laundering that incorporates these features of Chair. An agent (a) launders their agency where

(1) $a$ is morally responsible with respect to some domain $X$, and

(2) $a$ ensures that $b$ (some process, person, or entity) has some causal responsibility with respect to $X$, and

(3) a ascribes (implicitly or explicitly) morally relevant qualities to b's actions (e.g., relevance, neutrality, reliability), and

(4) in virtue of (2) and (3), a obscures the scope of their causal responsibility with respect to $X$, and

(5) in virtue of (4), a fails to adequately account for events within $X$ for which they are morally responsible.

This definition only gets us so far. It sets out the structure of agency laundering, which tracks and incorporates the structure of moral responsibility from Section 7.1.1. However, it does not explain the moral problem of agency laundering itself (if there is one). That's our next task.

There are several ways in which the chair may have acted wrongly. One possibility is that it is unjustifiable to eliminate phlogistology in any case. But let's leave that aside and assume that it's permissible to eliminate it based on its substance and the context. More important is that the chair's ascription of morally relevant qualities to the committee is misleading, and they have therefore deceived people about the process involved. Regardless of whether getting rid of P-studies is justifiable, the chair's obscuring their reasons and intentions in impaneling the committee do not appear justifiable. Others with whom the chair has a relationship have a claim to understand such an important facet of their professional lives.

A still deeper moral problem is that the chair's action allows them to avoid the core demand of responsibility, which is to provide an account. Regardless of whether the chair is meeting their role responsibilities with respect to the curriculum, they are forestalling others' ability to demand an account for the chair's actions within a domain of their legitimate concern. ${ }^{20}$ This is the defining feature of agency laundering, and it turns on the substantive account of responsibility given in

20 Two other accounts addressing causal and moral responsibility in the computing context are worth noting here. First, Daniel Dennett posits that machines may be credited with (i.e., responsible for) some tasks (e.g., Deep Blue beating Kasparov) but cannot be responsible for others (e.g., murdering 
Section 7.1.2. There, we explained that responsibility is first about social relations. We hold others responsible for their actions in part by forming reactive attitudes, and such reactive attitudes are key in understanding responsibility. However, our view is that moral responsibility is also a matter of whether agents are open to demands to justify their actions and whether it is appropriate for others to demand an account of their reasons and intentions.

Now we come full circle. Agency laundering involves a kind of misdirection (as in (2)-(4)). But, crucially, the misdirection undermines others' ability to demand reasons for an agent's actions. In other words, the laundering part of agency laundering cuts straight to the heart of what responsibility is by undermining the ability of others to ask the agent to provide an account.

Department members will be unable to ask the chair for their reasons and intentions in eliminating phlogistography, because the chair's actions look like formation of a committee that (apparently) deliberated about and then eliminated the subfield. Department members would reasonably believe that all the chair has to provide is an account of delegation to the committee. But an account that focused on the committee would not be an account of the chair's actual reasons and intentions, which are about engineering an outcome, not initiating a process to weigh things. ${ }^{21}$

It is worth explaining the role of condition (5) a bit further. What matters about (5) is that it distinguishes cases like Chair from structurally similar cases of delegation. Consider a variation in which the chair thinks P-studies should be eliminated, and they know that there are so few P-sympathists that any full committee will have a majority of P-eliminationists. Nonetheless, the chair delegates the curriculum decision to a committee because of their commitment to inclusive, democratic

Kasparov). Dennett, "When Hal Kills, Who's to Blame? Computer Ethics." We would argue that this difference tracks the causal/moral responsibility distinction, though that is not Dennett's claim. Helen Nissenbaum argues that the increased use of computing systems poses a threat to accountability, based on four key barriers. These include the problem of many hands, the existence of bugs that cause computing failures, the ability to use computers as scapegoats, and the separation of system ownership from legal liability for problems. In doing so she notes that distributed causal responsibility can function to obscure responsibility and blameworthiness. See Nissenbaum, "Computing and Accountability," 74. Our view of laundering can apply to each of the barriers she discusses but does not reduce to any of them. Consider the example of "blaming the computer" or pointing to the computer as the sole source of causal responsibility. That considered by itself would not seem to be a case of laundering, but instead just a straightforward denial of responsibility. If, instead, it included a process by which a party ensures the computer has causal responsibility, ascribes morally relevant qualities to the computer's actions, obscures the party's causal responsibility, and in so doing fails to adequately account for events for which the party is morally responsible, it could be laundering. In other words, merely blaming something else does not rise to laundering. Laundering is, we take it, more insidious in that it forestalls others' abilities to demand an account of actions within domains of their legitimate concern.

${ }^{21}$ Note that agency laundering does not require that one infringe one's substantive role responsibilities (except to the extent that one's role responsibility includes being transparent about one's causal responsibility). In Chair, for example, it is plausible that the chair was fulfilling their role responsibilities with respect to the department's curriculum. We return to this point in Section 7.4. 
department governance. As in Chair, (1)-(3) obtain. And (4) plausibly obtains, as the chair's causal responsibility in forming the committee may obscure their causal role in deciding to review P-studies. But the key difference is that the committee formation in "Democratic Chair" is not a sham, constructed so that the chair can avoid having to account for their actions regarding the curriculum. Just as in the original example, department members will reasonably believe that the action for which the chair should provide an account is the formation of the committee. But in democratic chair, that is the only action for which the chair should provide an account.

So that's the account. Let's turn to some cases. These will help us understand how predictive, automated decision systems can launder agency.

\subsection{FACEBOOK AND ANTI-SEMITIC ADVERTISING}

In 2017, ProPublica published a report detailing an investigation into Facebooktargeted advertising practices. ${ }^{22}$ Using Facebook's automated system, the ProPublica team found a user-generated category called "Jew hater" with more than 2,200 members. While two thousand Facebook users choosing to identify as "Jew hater" in their profiles seems like a lot, Facebook's platform helpfully informed the ProPublica team that it was too small an audience for an effective ad buy. To help ProPublica find a larger audience (and hence have a better ad purchase), Facebook suggested a number of additional categories. For example, it suggested including the category "Second Amendment," presumably because of some overlap in users' choices of interests in their profiles. ProPublica used the platform to select other profiles displaying anti-Semitic categories, and Facebook approved ProPublica's ad with minor changes.

Facebook's platform also allows clients to target ads by excluding profiles by age, geographic, and race and ethnic categories. For example, advertisers can target users in specific places and income ranges while excluding people with specific "ethnic affinities." Many of these affiliations are generated automatically, based on content users and their friends have liked or shared. In some cases it is not the category that creates a problem, but the purpose of the ad. Targeting an ad by age makes sense in some contexts (life insurance, toys) but is discriminatory in others (job recruitment). ${ }^{23}$

When ProPublica revealed the anti-Semitic categories and other news outlets reported similarly odious categories, ${ }^{24}$ Facebook responded by explaining that algorithms had created the categories based on user responses to target fields (e.g., answers to questions about education and hobbies). It also pledged to address the

22 Angwin, Varner, and Tobin, "Facebook Enabled Advertisers to Reach 'Jew Haters."

23 Note that Facebook has recently taken measures aimed at reducing discriminatory advertising (Levin 2019).

24 Oremus and Carey, "Facebook's Offensive Ad Targeting Options Go Far beyond ‘Jew Haters."” 
issue. But Facebook was loath to claim it had responsibility. Chief Operating Officer Sheryl Sandberg claimed in a public response that "[w]e never intended or anticipated this functionality being used this way." 25 That is no doubt true, though Facebook wishes to both sell advertising and employ as little labor as possible to monitor how that advertising functions.

Is it agency laundering? An agent (Facebook) launders its agency where

(1) Facebook has moral responsibility with respect to targeted advertising, and

(2) Facebook ensures that its algorithmic advertising process has some causal responsibility with respect to targeted advertising on its platform, and

(3) Facebook ascribes morally relevant qualities to its algorithmic advertising process's actions, and

(4) in virtue of (2) and (3), Facebook obscures the scope of its causal responsibility with respect to targeted advertising on its platform, and

(5) in virtue of (4) Facebook fails to adequately account for events within a domain for which it is morally responsible: specifically, the way in which its advertising platform helps target advertising to racists.

Each of these conditions appears to obtain. Certainly, Facebook has causal responsibility with respect to targeted advertising on its platform. A more difficult question is whether Facebook has role, or prospective, responsibility. The clearest sense in which they have role responsibility is that they have de jure authority over their platform, and they have a general responsibility to be good members of the broad community of people who use the platform. More specifically, they have (in our view) a specific responsibility to ensure that their platform does not facilitate racists to easily find an audience to whom they can advertise.

The claims that Facebook has such specific moral responsibilities will no doubt be controversial. Others may argue that Facebook has a moral responsibility to be a mere conduit of communication among members. ${ }^{26}$ That is unconvincing for a couple of reasons. For one, this case is about advertising. Any claims about how Facebook should structure information between end users tell us nothing about Facebook's responsibility vis-à-vis advertisers. Moreover, Facebook already acts as if it has responsibilities with respect to both content and advertising. It has community

25 Sandberg, "Last Week We Temporarily Disabled Some of Our Ads Tools."

26 Note that this is a possible moral claim that one might make about Facebook and other media organizations. This is a distinct question from what kinds of legal rights and obligations information intermediaries have in light of (inter alia) 104th United States Congress; an act to promote competition and reduce regulation in order to secure lower prices and higher quality services for telecommunication consumers and encourage the rapid deployment of new telecommunications technologies; European Union, Directive 2000/31/EC of the European Parliament and of the Council of 8 June 2000 on certain legal aspects of information society services, in particular electronic commerce, in the internal market (directive on electronic commerce); European Union, Regulation (EU) 2016/679 of the European Parliament and of the Council of 27 April 2016 on the protection of natural persons with regard to the processing of personal data and on the free movement of such data, and repealing Directive 95/46/EC (General Data Protection Regulation). Keller, "The Right Tools." 
standards, by which it judges and removes content, and it restricts certain kinds of advertising. ${ }^{27}$ In any case, agency laundering only requires that Facebook have general responsibilities within this domain.

Facebook's categories are derived in part by automated systems. It takes a handsoff approach, letting users generate profile information, letting an algorithm pick out characteristics from user profiles, letting advertisers peruse those categories, and letting an algorithm suggest compatible categories to build better ad target groups. Thus, Facebook ensures that an algorithmic process has causal responsibility (i.e., is a key part of the explanation) for what ads appear to whom on Facebook's platform. That's condition (2).

Facebook's business model includes allowing advertisers to target groups of people narrowly and effectively. It does this in a way that avoids the labor costs associated with human approval of ad targets or human oversight of ad categories and purchases. In so doing, Facebook implies that its algorithmically generated categories and suggestions are relevant to advertisers (otherwise, advertisers would have no reason to purchase ads). And the fact that one can place ads based on those categories without oversight implies that Facebook believes (at least implicitly) that whatever ads served to whatever audience are appropriate. These are morally relevant qualities, as per our third condition. The algorithms' causal responsibility and implication that they are appropriate obscure the scope of Facebook's causal responsibility (condition (4)).

Finally, in automating its advertising process, Facebook is able to claim that it "never intended or anticipated this functionality being used this way." It effectively distances itself from the fact that a system for which it is (causally and morally) responsible allows noxious (and in the case of discriminatory categories, illegal) advertising. That is, the causal responsibility of the algorithm's suggestions deflects from Facebook's causal responsibility in creating a platform that uses the algorithm, minimizes the labor that would be required to better monitor advertising categories, and profits from the automated system. Its attribution of morally salient characteristics (relevance, usefulness) presupposes that its optimization is consistent with Facebook's responsibilities, though it is not.

Here is where understanding Facebook's actions as agency laundering is a difference-maker. Conditions (1)-(4) describe several important moral features. But the crux of laundering is condition (5). The fact that Facebook is morally responsible with respect to targeted advertising means that it is appropriate to demand that Facebook provide an account of its intentions and reasons in facilitating racists in easily finding an audience to whom they can advertise. Facebook has inserted an automated procedure into its advertisement purchasing procedure, and it suggests that the algorithms are the natural object to scrutinize rather than Facebook's reasons and intentions with respect to building a system that deploys

${ }^{27}$ See, e.g., Facebook, "Community Standards Enforcement." 
them and lets them run with minimal supervision. In doing so, Facebook undermines the central feature of responsibility by deflecting demands for an account of Facebook's reasons, intentions, and actions in helping racists target advertise. Hence, the automated process is a mechanism by which Facebook launders its agency.

There are several potential rejoinders to our argument here. One might disagree about what Facebook's responsibilities are. One might argue instead that it is advertisers and users who bear responsibility for populating Facebook's categories with racist characteristics. Certainly, it is true that users populating categories with anti-Semitic and other racist ads bear responsibility for those actions, and any advertiser targeting ads based on such categories bears responsibility for doing so. But, as in Chair, that others have acted wrongly does not tell us much about Facebook's responsibility. One might further argue that Facebook has not laundered its agency because it has agreed to address the problem. But the fact that Facebook has indicated an intention to address these problems demonstrates that it is a problem within Facebook's control.

A related objection concerns the degree, or the severity, of Facebook's failure to fulfill its responsibilities (assuming that it has some). Perhaps Facebook knew of problems in how its algorithms functioned to allow malignant actions. But perhaps instead it was merely negligent. ${ }^{28}$ This is no doubt an area others will reasonably dispute. It does not matter for our analysis of laundering, though. Facebook laundered whatever degree of agency it had. Moreover, it can launder its agency even if it meets its substantive role responsibilities. That the advertising platform afforded the opportunity to target advertising in a racist way is something for which detailed explanation of intentions, reasons, and actions is warranted.

Another potential objection is that it may well be that no particular Facebook contractor or developer acted with discriminatory intent, alleviating any potential moral responsibility any of them might have for the outcome. ${ }^{29}$ However, Facebook's role responsibility is not reducible to any particular individual developer within Facebook. Rather, the company's responsibility is better understood as widely distributed across its contractors, employees, and other stakeholders. Moreover, Facebook's platform is complex, and the consequences of its operations over time

28 One can frame this as a question of capacity responsibility. That is, if Facebook did not have epistemic access to the relevant information about the possibility of misuse, it would not have the necessary capacity to be morally responsible. Note here that epistemic access is not limited to actual knowledge, but the ability to garner it under reasonable conditions. Hence, Facebook's moral responsibility will turn on the degree to which it could reasonably have known about potential for misuse. And that would define its degree of agency laundering.

One further complicating issue is mitigation. Facebook or another social media company might use its suggestion system to better understand relations among (for example) racists or purveyors of disinformation to promote anti-racist or epistemically sound information. The degree to which that would mitigate or deepen laundering is a question beyond what we can cover here. Thanks to an anonymous reviewer for making this point.

29 Binns, "Fairness in Machine Learning: Lessons from Political Philosophy." 
are impossible to predict. Coeckelbergh and Wackers argue that organizations deploying such complex, vulnerable systems have obligations to manage their operations not only legally, but with a certain positive "imagination" regarding systemic crises or other harms. ${ }^{30}$ In other words, it is unjustifiable to simply let such complex systems run their course and cause harm.

There is a further, related question about whether the conception of responsibility we have outlined here is properly attributable to collectives. There is significant philosophical debate about collective responsibility, and we cannot do it justice here. But we can note two things. First, the accounts of responsibility we outline in Section 7.2 need not be limited to individual wills. Certainly, we do have reactive attitudes toward collections of people, and those targets may be apt. Further, it seems plausible to attribute reasons to groups, in which case it seems plausible that such a group may be responsible in the sense that it ought to be the case that the collective be accountable. Second, even if it is the case that a collective's responsibility is reducible to the responsibility of its individual members, this would imply that those individuals have laundered their agency. In any case, whatever responsibility there is, Facebook's reliance on algorithms to do work and to explain its failures is (on the conception outlined here) an instance of agency laundering.

\section{$7 \cdot 4$ UBER AND DRIVER MANAGEMENT}

Another private-sector example shows how our concept of agency laundering can distinguish between structurally similar cases. The ride-hailing company Uber has received substantial social, regulatory, and academic criticism based on its AIdriven, algorithmic systems. Uber uses such systems to map routes, track passengers, monitor drivers, anticipate demand, steer driver behavior, and (at one point) identify and deceive regulators. Many of these uses have been criticized elsewhere on the grounds that they are deceptive, unfair, opaque, or even illegal. ${ }^{31}$ Our task here, though, is to consider whether any are instances of agency laundering and, if so, whether analyzing them as agency laundering sheds light on moral concerns with Uber's practices.

Recall two issues that we touched on in Chapter 5: how Uber uses algorithmic systems to keep its drivers working. One way is by providing reminders of individual drivers' goals. For example, the Uber app might display a message that the driver is very close to their goal of earning $\$ 50$ for their shift, which may induce them to take more riders. Similarly, Uber at times sends drivers their next ride requests before

30 Coeckelbergh and Wackers, "Imagination, Distributed Responsibility and Vulnerable Technological Systems: The Case of Snorre A."

${ }^{31}$ One tool, named "Greyball," was developed to surreptitiously ban users who Uber believed were violating the company's terms of service. Uber eventually used Greyball to surreptitiously ban people Uber believed to be government regulators investigating whether Uber was operating illegally. See Isaac 2017. 
they have delivered their current rider. This creates a kind of "queue effect," much like video platforms that keep people watching by immediately starting the next episode of a series..$^{32}$ A number of critics - including drivers - object to these practices on the grounds that they rely on nonrational mechanisms or are manipulative. ${ }^{33}$

Another way that Uber gets drivers to keep working involves the prospect of dynamically priced fares, which allows drivers to increase their per-hour earnings by driving during high-demand/low-supply periods. When there are lots of passengers seeking rides and relatively few drivers working, Uber will charge higher (surge) prices and drivers thus earn more. Uber's driver app will often prompt drivers to work at times that Uber anticipates will be high demand. So, it might say that, for example New Year's Eve will probably have surge pricing. ${ }^{34}$ However, such prompts do not guarantee surge pricing, and drivers do not know when they accept a ride whether it will be surge-priced. In some cases, the Uber app estimates surge pricing, but fares during that period are normal, either because demand does not materialize or because enough drivers are working to offset the demand. ${ }^{35}$

These two cases are structurally similar: app-based mechanisms that prompt drivers to work somewhat more than they would have otherwise. Recall our argument that only surge pricing interferes with people's valuable freedoms. Relatedly, only the surge pricing appears to be a case of agency laundering. To see this, begin by running both through our understanding of laundering.

(1) Uber has moral responsibility with respect to fielding drivers, and

(2) Uber ensures that its algorithm has some causal responsibility with respect to fielding drivers, and

(3) Uber ascribes morally relevant qualities to its app-based prompts to drivers, and

(4) In virtue of (2) and (3), Uber obscures the scope of its causal responsibility with respect to fielding drivers, and

(5) In virtue of (4), Uber fails to adequately account for events within a domain for which it is morally responsible: specifically, the way in which its interface induces driving.

Conditions (1) and (2) are clear enough. Although Uber claims to be a technology company merely connecting riders and drivers through a platform, it nonetheless plays a large role in getting people to both drive and ride. It enters into contractual relationships with drivers and riders, maintains standards for drivers and equipment, subjects drivers to background checks, adjudicates disputes, and so forth. And there is no question that its algorithms are a key part of the explanation of which drivers are driving when. Uber ascribes morally relevant features to the algorithms: that they

32 Scheiber, "How Uber Uses Psychological Tricks to Push Its Drivers' Buttons."

33 Scheiber; Calo and Rosenblat, "The Taking Economy: Uber, Information, and Power."

34 Rosenblat, Uberland, $128-132$.

35 Rosenblat, 98-100. 
reflect drivers' own goals, that they are reliable, that they are based on a neutral assessment of facts on the ground (condition (3)).

The differences in the cases concern conditions (4) and (5).

Begin with the case of goal-reminders and queuing effects. It is difficult to see how Uber obscures its causal responsibility in incentivizing driving when it uses these tactics to spur drivers into taking more rides. Certainly, Uber is drawing on (or even exploiting) behavioral psychology, and behavioral psychology is an essential part of the explanation of drivers' decisions to drive. But that fact, and the fact that Uber has set up a system in which algorithms instantiate such strategies, is not obscured.

Now consider condition (5). Here, too, it is difficult to see how Uber fails to adequately account for events within a domain for which it is morally responsible. As a provider of ride-hailing services, Uber has an interest in keeping enough drivers on the road, and it is using a straightforward tactic to promote this interest. Further, Uber has been clear about the practice. In a recent New York Times article, a spokesperson for Uber describes goal-reminding and queuing as ways to incentivize driving. ${ }^{36}$ As far as we can tell, Uber does not launder its agency when it uses goalreminders and queuing.

One plausible counterargument here is that, at least in extreme cases, using such tools undermines drivers' wills so much that it obscures the scope of Uber's causal responsibility. Perhaps the interface is sufficiently gamified that users have hallmarks of addiction, or perhaps the quality of drivers' wills is so degraded that decisions to drive do not count as drivers' own. In that case, Uber's causal responsibility would be far greater than it appears and any adequate account of Uber's responsibility would include an explanation of how it circumvents drivers' wills. That possibility is worth both empirical and philosophical examination. Nonetheless, at least weaker forms of nudging seem well within the range of responsible employer behavior and not cases of agency laundering.

Contrast the goal-reminders and queuing with the surge-pricing case. Uber uses machine learning techniques to predict high-demand/low-supply times and uses those predictions to prompt drivers to work. This does seem to obscure Uber's causal responsibility in fielding drivers, per condition (4). The judgment that surge pricing is likely to occur appears to be an inference about how the world outside Uber is operating, and Uber is merely reacting to it. Indeed, in comments pertaining to the phenomenon of surge pricing, Travis Kalanick (Uber's cofounder and former CEO) said, "We are not setting the price. The market is setting the price." ${ }^{37}$ In fact, Uber is causally responsible for setting up a system in which there are pay differentials (where driving at surge times is more attractive to drivers) and then using those facts to induce driving. Surge periods are not a natural feature about the world that Uber measures, but a period defined and deployed by Uber.

37 Clark, “Uber Denies Researchers' 'Phantom Cars' Map Claim.” 
More important, though, is condition (5). By predicting surge pricing and signaling the likelihood of surge pricing to drivers, Uber simultaneously exploits surge pricing and makes it less likely. In other words, by using surge pricing as an inducement to drivers seeking a better wage, Uber helps ensure that supply matches demand more closely. Thus, it creates for drivers reasonable expectations of better pay and fails to meet them. Then, when the prices are not offered, Uber tells the drivers it is the market that is making the decision, not Uber. But this is a failure to account for the situation a driver finds themself in when, for example, they have driven to Times Square on New Year's Eve under Uber's advice that there will be a surge and then find that the surge has disappeared. As Alex Rosenblat observes, "When drivers follow this advice and find that they have been dispatched to pick up a passenger for a nonpremium-priced ride, meaning that surge pricing has disappeared, they feel tricked." ${ }^{8} 8$ It is not the market that reached out to the driver to quell the surge. It is not the market that decided how Uber's payment system works. Rather, it is Uber that sets up a system where a driver who responds to its enticements may not get surge rates if the campaign to get drivers to an area has worked. And this is the action within its domain of moral responsibility for which Uber owes an account. Uber's claim that it is simply the market's doing is an inadequate account, satisfying condition (5). Thus, Uber launders its agency.

So our conception of agency laundering is sensitive enough to distinguish between different uses of algorithmic systems to influence driver behavior. The next question is whether analyzing each in terms of agency laundering adds something of value beyond simply analyzing Uber's responsibilities to its employees. We believe that it does. The laundering analysis emphasizes the fact that use of tools (committees, bureaucracies, technologies) may be a way to simultaneously violate duties and undermine accountability. This is a way to show that laundering adds something. By calling it laundering, we can make clear what is happening. But more importantly, our argument picks out a discrete moral infirmity, viz., eroding others' ability to demand Uber provide an account of its reasons and intentions. In Uber's case, use of a tool to both predict surge pricing and induce drivers looks similar to use of other prompts. One might be tempted to think of it as a case of nudging (or perhaps of manipulation). But that would miss the fact that by tying the process to a prediction about facts on the ground, Uber can deflect attention from its own responsibility for creating a situation in which it simultaneously predicts surge pricing and makes it less likely.

\subsection{VAMS AND TEACHER EVALUATION}

Facebook, Uber, and other large technology firms receive substantial attention. It would be a mistake, however, to think that agency laundering is primarily the

$3^{8}$ Uberland, p. 129. 
province of the private sector. The depth and importance of agency laundering may be even greater in public agencies. To demonstrate, we will reexamine Houston Schools' use of EVAAS. Recall that EVAAS is in practice not auditable for two interrelated reasons. First, all of its scores are so deeply interconnected with other scores that the only way to recalculate a score is to recalculate them all. Second, recalculating all of the scores is a complex task and thus very costly.

Despite its shortcomings, Houston Schools defended its use of EVAAS on the grounds that it reliably measures student progress. ${ }^{39}$ But this claim, even if true, is largely irrelevant to the question of whether the use of EVAAS is justified. Student progress and the contributions an individual teacher makes to student progress are distinct quantities. To measure one is not to measure the other. Indeed, the American Statistical Association (ASA) issued a statement in 2014 pointing out that most studies conclude that teachers have only a marginal effect on the test scores that VAMs (such as EVAAS) take as inputs. ${ }^{40}$ So, even if EVAAS reliably measures student progress, this is a poor proxy for teacher effectiveness.

Has the school district laundered its responsibility for firing teachers? We think so.

(1) Houston Schools is morally responsible with respect to hiring, firing, and promoting teachers, and

(2) Houston Schools ensures that EVAAS has some causal responsibility in making those determinations, and

(3) Houston Schools ascribes morally relevant qualities to EVAAS, and

(4) In virtue of (2) and (3), Houston Schools obscures the scope of its causal responsibility with respect to hiring, firing, and promoting teachers, and

(5) In virtue of (4), Houston Schools fails to adequately account for events within a domain for which it is morally responsible: specifically, the "exiting" of teachers deemed ineffective through EVAAS.

In virtue of Houston Schools' role as an employer, the first condition is met. When Houston Schools implements EVAAS to aide in personnel decisions it meets the second condition. Houston Schools meets the third condition implicitly by using EVAAS for high-stakes decisions. It meets the third condition explicitly by invoking EVAAS's reliability in measuring student progress as a reason in favor of using EVAAS. The fourth condition is met when Houston Schools repeatedly refers to one good thing that EVAAS does (measure student progress) to obscure the fact that Houston Schools is implementing a system in which teachers are fired based on measures for which the teachers are not responsible (recall the statement from the ASA mentioned earlier). Finally, the fifth is met because teachers who are fired on account of their EVAAS scores are given a faulty accounting of why they were fired. They are told they are being fired for being ineffective, when, given EVAAS's flaws,

39 "Defendant's Original Answer and Defenses," in Houston Fed of Teachers, Local 2415 v. Houston Ind Sch Dist, 251 F. Supp. 3d.

4० Morganstein and Wasserstein, "ASA Statement on Value-Added Models," 2. 
this is likely not the case. Hence, understanding Houston Schools' actions as laundering shows us that there is something going on beyond lack of transparency; the mechanism of evaluation positively misdirects those who would seek reasons for how teachers are treated. It forestalls teachers' ability to demand an account for the school district's actions, within a domain of their legitimate concern.

Note that Houston Schools uses EVAAS while fulfilling its public function of managing an education system. That means that the public has a collective stake in how the system functions and has an interest in the actions Houston Schools undertakes. Hence, the fact that Houston Schools' laundering makes accountability all the more difficult matters in a way that accountability of private firms does not; it suggests that use of EVAAS must conform to standards of public reason, rather than aligning only to the isolated wishes of the district. ${ }^{41}$

\subsection{COMPAS AND CRIMINAL SENTENCING}

So far, we have described agency laundering in both private-sector and public-sector cases. And in the Uber case we saw how use of algorithmic decision systems will not be agency laundering where the agent does not obscure their causal responsibility for outcomes. We will return to Loomis to demonstrate how a public entity can avoid agency laundering by making clear their moral responsibility for an outcome.

Loomis and COMPAS have been the subjects of significant criticism. However, we think that the Wisconsin Supreme Court's opinion in the case shows how actors can avoid agency laundering in deploying algorithmic systems. Hence, the case shows that our understanding of agency laundering is not so broad as to be meaningless.

A trial court launders its agency where

(1) the trial court has moral responsibility with respect to sentencing, and

(2) the trial court ensures that COMPAS has some causal responsibility with respect to sentencing, and

(3) the trial court ascribes morally relevant qualities to COMPAS, and

(4) in virtue of (2) and (3), the trial court obscures the scope of its causal responsibility with respect to sentencing, and

(5) in virtue of (4), the trial court fails to adequately account for decisions pertaining to sentencing, specifically the decision to sentence Loomis in the maximum range.

The trial court certainly has moral responsibility with respect to sentencing. But did the trial court ensure that COMPAS had some causal responsibility with respect to sentencing? The judge referenced Loomis's risk scores and they plausibly had an effect on sentencing. This, though, was only one of the factors the judge described.

41 Binns, "Algorithmic Accountability and Public Reason." 
He also considered important the conduct Loomis admitted as part of the read-in charges and Loomis's conduct while under prior supervision. Let's interpret this as giving some degree of causal responsibility to COMPAS. It is, after all, at least plausible that the COMPAS score is a key part of the explanation for Loomis's sentence. The court's use of COMPAS implies that it is useful, reliable, and fair, which are morally relevant qualities, per condition (3).

The question of agency laundering in Loomis turns on conditions (4) and (5). Although the judge in the case referenced the COMPAS assessment in his decision, he also indicated that his own judgment (based on Loomis's conduct and history) led him to a similar conclusion. There is some possibility that the judge was confabulating by ascribing his own reasons to the outcome COMPAS reached. If that's true, it would not be that the use of COMPAS obscures the trial court's causal responsibility. Rather, it would be that the court's description of its reasons obscures the scope of COMPAS's causal responsibility.

The key issue, though, is whether the trial court fails to adequately account for decisions pertaining to sentencing. Consider the following from the Wisconsin Supreme Court's decision.

We determine that because the circuit court explained that its consideration of the COMPAS risk scores was supported by other independent factors, its use was not determinative in deciding whether Loomis could be supervised safely and effectively in the community. Therefore, the circuit court did not erroneously exercise its discretion. $^{42}$

The passage makes clear that tools like COMPAS cannot be used alone, and use of such scores has to be supported by other factors that are independent of the tool. Similarly, the court required that courts weigh all relevant factors in order to sentence an individual defendant, ${ }^{43}$ and it prohibited trial courts from using scores to determine whether to incarcerate a person or not, to determine the length and severity of sentence, and to determine aggravating or mitigating factors in sentencing. ${ }^{44}$ And the court required that any PSI that uses a COMPAS report carry a number of warnings about the limitations of such reports.

The supreme court's Loomis opinion places responsibility squarely on the trial court in using tools like COMPAS. It prohibits trial courts from relying completely on the COMPAS algorithm, and it requires trial courts to use other factors to support any use of risk assessment algorithms. Hence, the court forecloses the ability of trial courts to use algorithms as a way to distance themselves from responsibility. Thus, Loomis addresses condition (5), and it is not a case of agency laundering. ${ }^{45}$

42 Wisconsin v. Loomis, 881 N.W.2d paragraph 9.

43 Wisconsin v. Loomis, 881 N.W.2d paragraph 74.

44 Wisconsin v. Loomis, 881 N.W.2d paragraphs 88-98.

45 Note that Loomis demonstrates another way one can launder even while fulfilling one's substantive role responsibilities. Imagine that the trial court had deliberated about its decision but did not explain 
Deploying tools like COMPAS could certainly be a means by which courts (and others in the criminal justice system) can launder their agency. However, the Loomis decision is tailored precisely to avoid that. Hence, it appears to be a good test case for our view. It is the use of an algorithmic system where one does not launder their agency. As a result, it can demonstrate how other actors may fail in their moral responsibilities, even where their actions superficially resemble the Loomis court's. The court did not forestall others' ability to demand an account for its actions within a domain of their legitimate concern, but a different court (or different actor within a criminal justice system) might do so by failing to provide its own reasons for decisions.

\section{$7 \cdot 7$ RELATED CONCEPTS AND CONCERNS}

\subsubsection{The Responsibility Gap}

Agency laundering can help shed light on some other concepts related to moral issues in technology. One of these is the "responsibility gap." In a 2004 article, Andreas Matthias argued that in some cases a technological system may be sufficiently sophisticated that no person or persons are responsible for the outcomes it causes. ${ }^{46}$ The idea is that machine learning systems may be so opaque to human developers and users that it is impossible to predict how those systems will behave. Where such systems cause harm, it may be (on Matthias's view) a mistake to attribute responsibility to the developer, the owner, or any other person. The rules by which machine learning systems act "are not fixed during the production process, but can be changed during the operation of the machine, by the machine itself." 47 These actions do not mesh with traditional accounts of responsibility "because nobody has enough control over the machine's actions to be able to assume the responsibility for them." ${ }^{8}$ He provides several examples. One is an elevator system that, having used an AI system to adapt to use patterns over time, leaves an executive stranded and late for a meeting. Another is a machine learning system to diagnose lung cancer, but which has a high false-positive rate (and causes emotional and financial stress to people diagnosed). Yet another is an AI children's toy that, in learning to navigate a new home environment, injures a child.

There has been a great deal of discussion of the responsibility gap in the years since Matthias's article was first published. Here, we want to illustrate how agency

its reasoning for the sentence. Suppose instead it merely wrote that it agreed with the COMPAS report's assessment with no further comment. That would obscure the scope of the court's causal responsibility and would fail to provide an adequate account of the decision. But in that case, the court would not have violated some other substantive role responsibility.

$4^{6}$ Matthias, "The Responsibility Gap: Ascribing Responsibility for the Actions of Learning Automata."

47 Matthias, 177 (emphasis in original).

$4^{8}$ Matthias, 177 . 
laundering is distinct from responsibility gaps and how it can explain where responsibility fits in the gaps.

Note first that Matthias's conception of the responsibility gap focuses on an automated system's causal responsibility for some outcome. In the toy case, Matthias posits that the responsibility gap pertains to the action of knocking over and injuring the child. Our account of agency laundering, however, considers a wider range of actions. Imagine that the toy manufacturer developed, marketed, and sold the toy without fully testing its ability to knock over and injure a toddler. The manufacturer would seem to have causal and role responsibility with respect to whether its toys injure children (condition (1)). It would also ensure that the toy has causal responsibility for whether it injures children (as Matthias describes the case, the child's injury is explicable only by describing how the toy operates) (condition (2)). By selling the toy, the manufacturer attributes morally relevant qualities to the toy (age appropriateness, safety) (condition (3)). It would also be difficult to provide an adequate account of a toy manufacturer's distribution of a toy that has the affordances (size, weight, mobility, unpredictability) to knock over a small child (condition (5)).

The question, then, is whether the manufacturer obscures the scope of its causal responsibility with respect to the injury (condition (4)). Nothing in the example (either Matthias's version or ours) suggests that it does. However, if the manufacturer were to posit a responsibility gap (e.g., by saying that the machine learning process was opaque, and hence the manufacturer could not anticipate injury), that would fulfill condition (4) and be an instance of agency laundering. In other words, invoking the idea of a responsibility gap is a mechanism by which people may launder their agency.

There are other possibilities as well. One might set up a system expressly to avoid being held to account. Such a scenario would appear to be a form of preemptive laundering, and it would be advanced by whatever responsibility gap it creates. A different possibility is that one creates a gap between one's actions and outcomes for good reasons but, in so doing, ensures that there will be a responsibility gap. Suppose, for example, an agency responsible for assessing how likely persons accused of a crime are to reoffend. To address a known problem of arbitrary assessments by human decision-makers, it deploys a system similar to COMPAS (while acknowledging biases similar to those in COMPAS). This would look like a case similar to democratic chair in Section 7.3. The agency's use of the system would not be a means to avoid having to account for some other action. Rather, it is the decision to deploy the system that requires an account, and that decision is not obscured. ${ }^{49}$

We leave open whether there are genuine cases of responsibility gaps - that's a topic others have addressed more thoroughly than we can do here. ${ }^{50}$ But our analysis of agency laundering requires thinking about role and causal responsibilities of people who deploy technologies like those Matthias contemplates. That

49 Thanks to a reviewer here for pointing out these possibilities and noting their similarities to "Chair" and "Democratic Chair."

50 Johnson and Verdicchio, "Reframing AI Discourse." 
forces one to consider a wider range of actions than the operations of an AI system and can help distinguish genuine responsibility gaps from responsibility obfuscation and agency laundering.

\subsubsection{Bias Laundering, Masking, and Humans in the Loop}

At a 2016 conference sponsored by the Society for the Advancement of SocioEconomics, Maciej Cegłowski stated that "machine learning [is] an ingenious way of disclaiming responsibility for anything. Machine learning is like money laundering for bias." ${ }^{11}$ Although Cegłowski does not spell out what laundering is or why it matters morally, there do seem to be some points of similarity and difference worth noting. What Cegłowski's comment picks out is the ability to obscure something important and deflect disapproval. So if an algorithm (e.g., for predictive policing) is built on criminal justice data, which is itself based on overpolicing Black communities, the algorithm may be a mathematically neutral tool that reflects biases that already exist. The tool's neutrality can appear neutral tout court to the extent that one fails to examine the bias in the underlying data sources.

However, our understanding of agency laundering is a general account of laundering, and it is broad enough that it encompasses bias laundering. Agency laundering can obscure many different kinds of wrongs and limiting the concept to bias laundering would fail to capture them. Likewise, there is no need to link laundering tightly with machine learning or algorithmic decision-making. As we've explained, any process or socio-technical system can be a mechanism for laundering. More importantly, our account explains just how laundering is related to responsibility, both structurally and morally. Finally, in our view the thing that is laundered is typically agency, and that is typically the appropriate target of analysis. ${ }^{22}$ One might at times act as an agent, yet launder responsibility, but in any case these are the things laundered. Thus, while we agree that machine learning can be a means of disclaiming responsibility, just what it means to "disclaim responsibility" and just what it is that one is responsible for are difficult questions to answer. This chapter is an attempt to do just that.

A similar concept is "masking" or the intentional use of algorithmic systems to obfuscate discrimination. ${ }^{53}$ Barocas and Selbst describe masking as a way of using data mining to return discriminatory results while hiding whatever discriminatory

${ }^{51}$ Cegłowski, "The Moral Economy of Tech." Thanks to Suresh Venkatasubramanian for pointing us to this talk.

52 We appreciate an anonymous reviewer raising the question of whether there are cases where one maintains agency but launders accountability instead. Our sense is that any such case would involve minimizing one's agency. In other words, accountability is the thing that is avoided, and one avoids it by laundering the degree to which one is (morally) responsible, which is in turn a function of a person's agency in a process. Likewise, money laundering is a way to forestall accountability, and it is the laundering of some other thing (viz., money) that helps avoid the accountability.

53 Barocas and Selbst, "Big Data's Disparate Impact," 692-693, 712-714. 
intent one might have behind an information system. Certainly, masking could be part of laundering. However, the other elements of laundering - relevant role responsibilities, ascription of morally relevant qualities, tension with fundamental aspects of responsibility (viz., accountability) - are not necessarily elements of masking.

There is a third important issue related to socio-technical systems, responsibility, and moral liability. The distinction between systems with humans in and out of the loop are well established. Systems employing humans in the loop include things like automated cars that provide for human override, autonomous weapons systems that require humans to approve strikes, and content moderation in which humans help teach algorithms what content is objectionable and make decisions in cases for which automated systems are not yet adept. Control in such systems is itself a complicated concept, and there is an active area of scholarship surrounding whether (and if so, how) there can be meaningful human control even for systems that leave humans out of particular decision loops. ${ }^{54}$

Of particular importance for our project is that having humans in the loop may itself obscure causal and moral responsibility. Ben Wagner notes that there are many purportedly automated systems that rely on humans to take an active role, fix mistakes, or replace system decisions. ${ }^{55}$ However, he argues that the actual human role may be compromised by the design of the system. For example, there may be insufficient time to make decisions, they may grow weary or inured to a process, or they may lack sufficient training and experience to make good decisions. He outlines a number of criteria important in determining whether systems are "quasiautonomous," such that humans in the loop "have responsibility but little agency" (or, in our usage, humans have causal but not capacity responsibility, and hence cannot be morally liable).

Madeleine Elish considers similar scenarios in which human actors have a causal role within socio-technical systems (including AI). ${ }^{56}$ She argues that responsibility for outcomes may be misattributed to human actors within such systems, creating a kind of "moral crumple zone" that protects the system from attributions of responsibility. In our conception, humans' causal responsibility could obscure the causal responsibility of a technical system (of course it cannot obscure the moral responsibility of a technical system, for such a system does not have capacity responsibility).

The systems that Wagner and Elish envision are ones that could potentially launder agency (though not necessarily). Suppose, for example, an autonomous vehicle has a human in the loop, but the human has too little time to respond when needed and causes an accident. That would seem to fulfill the conditions (1) and (2):

54 Santoni de Sio and van den Hoven, "Meaningful Human Control over Autonomous Systems:

A Philosophical Account."

55 Wagner, "Liable, but Not in Control?"

${ }^{5}$ Elish, "Moral Crumple Zones." 
some entity with moral responsibility has ensured a human has causal responsibility. The questions are whether placing a human in the loop attributes morally relevant qualities to the human's actions (efficacy, perhaps), whether doing so obscures the causal responsibility of the larger system and thereby fails to adequately account for the moral responsibility of the larger entity. What is key for our view, though, is that the mechanism for laundering need not be technological at all; that is, humans in the loop can be a means of laundering just as well as automation itself.

\subsubsection{Concerns}

One potential objection to our conception of agency laundering is that it is merely a metaphor and as such does not add a great deal to our ability to analyze and evaluate the relationship between information technologies and responsibility. There are a couple of reasons to think otherwise. Using the concept of laundering takes its cue from the idea of money laundering, which is of course metaphorical. Crooks do not literally wash money. Rather, they obscure its sources by mixing it with money from legitimate sources. Hence, whatever actions work to obscure the source of illicit funds also serve to launder those funds. Laundering is a way of obscuring the source of morally weighty states of affairs by mixing actions with technologies, procedures, or bureaucracies. Part of the value of using the laundering metaphor (for both money and agency) is that it plays a "descriptive role in helping a lay person understand" what the underlying phenomenon is. ${ }^{57}$ That is, a metaphor can help capture the gist of a concept and, in this case, give people an intuitive grasp of the underlying concerns before following the entire argument.

Note, too, that the concept of agency laundering can help us both to make judgments in difficult cases and to explicate antecedent moral wrongs more fully. So, for example, in the Facebook case, it is unclear just what the moral wrong is in using an automated targeted advertising system that bad actors can exploit. It is plausible that Facebook did not act wrongly in developing and using such a system. However, the advertising platform is still within a domain for which Facebook has moral responsibility, and its conflation of its actions with an automated system's actions undermines the foundation of responsibility, viz., providing an account.

Similarly, the concept of agency laundering can explain why Uber acts wrongly in some cases (surge pricing) but not in others (goal prompts, queuing). ${ }^{5}$ Both actions are within Uber's domain of responsibility, and both are actions where there is an open question about whether Uber infringes its substantive role responsibility. Our account of agency laundering can help evaluate what, if anything, Uber does wrong.

57 Thanks to an anonymous reviewer for this language and description. In this signaling respect, our use of a metaphor here works similarly to the "crumple zone" metaphor in Elish, discussed in Section 8.2.

$5^{8}$ Note that there may be other, non-laundering moral wrongs involved in goal prompts and queuing, as discussed in Section 7.5. 
The account may be of particular use in public-facing cases, where organizations have a remit to serve the public and derive legitimacy from public trust and support. In cases like Houston and Loomis, the possibility of socio-technical systems forestalling persons' abilities to demand an account of organizations' actions within a domain of legitimate concern is particularly important. Drawing on the metaphor of laundering here helps capture content of the concept.

A further advantage of our account is that it may help in understanding what kinds of rights to explanation people have in the context of automated or algorithmic decision systems, for example in the GDPR. ${ }^{59}$ As we discussed in Chapter 4, such a right (if there is one) is generally discussed as an individual right in the face of adverse decisions. ${ }^{60}$ But agency laundering is a problem not just for individuals whose interests have been affected. It is also a general problem, and our arguments about laundering and forestalling others' abilities to demand an account within areas of their legitimate interest extend further. After all, how a massive social media company helps target ads, how an international employer of drivers with millions of users and drivers induces use, how a school district evaluates and fires teachers, and how a criminal justice system wields its power are areas of general legitimate interest, regardless of whether a particular individual has a claim to an explanation of a discrete event.

\subsection{CONCLUSION}

Our goals in this chapter were to, first, explain a type of wrong that arises when agents obscure responsibility for their actions. We have outlined this type of wrong and called it "agency laundering." Second was to draw on several cases to help specify our account of agency laundering. We have argued that some of these (Facebook advertising, Uber's surge-pricing prompts, Houston Schools' use of EVAAS) involve laundering and two (other Uber prompts, use of COMPAS in the Loomis case) do not. Third, we have argued that analyzing these cases in terms of agency laundering both helps understand the cases and adds something morally. Lastly, we have distinguished agency laundering from other relevant concepts.

We have not given the final word on agency laundering here. One further question concerns the degree to which laundering must be intentional. In other words, can a person who uses a tool to make decisions launder their agency inadvertently? This appears compatible with our definition of agency, though the moral importance of such laundering warrants further consideration. Another

59 Regulation (EU) 2016/679 of the European Parliament and the Council of 27 April 2016 on the protection of natural persons with regard to the processing of personal data and on the free movement of such data and repealing Directive 95/46/EC (General Data Protection Regulation), 2016 O.J. (L 119).

6o Wachter, Mittelstadt, and Russell, "Counterfactual Explanations without Opening the Black Box: Automated Decisions and the GDPR"; Selbst and Powles, "Meaningful Information and the Right to Explanation"; Kaminski, "The Right to Explanation, Explained." 
question concerns how widely the concept of agency laundering applies. A few people with whom we've discussed this project have asked whether large-scale social processes (e.g., political events and movements) can serve either as mechanisms or as sites of laundering. Perhaps so, though that would involve sorting through complex issues of causal responsibility and conceptual questions of capacity responsibility. 